\title{
Widening the Understanding of Risk Approaches by Comparing Definitions from Different Disciplines
}

\author{
Gabriele Berg-Beckhoff, Peter Wiedemann, \\ Balázs Ádám, Joachim Schüz, \\ Kristian Breum Ølgaard, \\ Pernille Tanggaard Andersen, \\ Steven Ndugwa Kabwama and Jesper Bo Nielsen
}

Additional information is available at the end of the chapter

http://dx.doi.org/10.5772/intechopen.70074

\begin{abstract}
The aim of this chapter is to critically reflect definitions of hazard, risk, and risk perception and their assessments used in different scientific disciplines and give examples of the potential implications for scientific discussions, knowledge management, and risk communication. Scientists with backgrounds in public health, psychology, environmental health, occupational health, engineering, sociology, and medicine were asked for a definition of hazard, risk, risk assessment, and risk perception seen from their specific scientific disciplines. Hazard is generally seen as an adverse event or condition. For most risk definitions, probability and severity are important aspects. Often a quantification of risk is desired, whereas risk perception is seen as a subjective appraisal and a cognitive construct. As risk perceptions are based on a combination of knowledge and individual values and affects, it may not provide a reliable guidance for risk management decisions on a societal level. Discipline differences are mainly connected to terminology and interpretation of key concepts, but the differences are based on different tasks and perspectives. For dealing with controversies in science across disciplines, an acceptance and appreciation of terminology and perspectives from different scientific disciplines are needed to ensure a transparent risk assessment process.
\end{abstract}

Keywords: risk, hazard, risk perception, risk assessment, multidisciplinary 


\section{Introduction}

The aim of this chapter is to critically reflect on definitions used in different disciplines during the procedure of risk management. Knowledge management is an important part of risk management and can be defined as a collaborative and integrated approach to the creation, capture, organization, access, and use of an intellectual asset [1]. This definition underlines the importance of knowledge management in risk management when different disciplines work together to identify the hazard, assess the risk, and finally predict mitigation mechanism [2]. To facilitate communication between different disciplines, we compared how risk management was approached in different disciplines. We recognized that harmonization of these approaches or definitions would be contraproductive as it would undermine the variety of knowledge and the tasks and perspectives of the different disciplines during the process of risk management. We, therefore, suggest to widen the understanding through appreciation of these differences between disciplines and not to harmonize definitions.

\section{Method}

The following disciplines were involved: public health, psychology, environmental health, occupational health, engineering, sociology, and medicine. The selection was made to get a wide variety of disciplines working in different areas but all with a link to risk and risk management. All selected participants have coauthored this chapter. They were recognized experts of risk-related disciplines. They expressed their opinions and synthetized conclusion in a reiterative process. Each scientist was asked to present his/her own views on the given topics. The following questions were developed to get comparable responses from the participants: What is hazard and risk? How is hazard/risk assessed and which practice of hazard identification and risk assessment is used? and How is risk perception defined? The results were summarized, commented, and discussed by all authors. This method is appropriate as it allows and discusses different opinions. The aim was not to agree on one set of definitions, but critically reflect on the discipline-related definitions of hazard, risk, and risk perception, and their assessments.

\section{Introduction in risk research}

Risk is human being's attempt to understand and deal with life's dangers [3]. Thus, the main reason for talking about hazard and risk is to have a sufficiently accurate perception of the situation to make decisions and manage situations in a manner minimizing the probability of adverse effects. In some instances, these decisions are strictly personal and have implications for the individual only, but in other cases, the decision may have implications for larger groups of people, even for the whole population, or for the environment. Disciplines predominantly dealing with numbers and quantifications define risks based on a calculable phenomenon; biological, natural, and technological scientists define risks as objective reality (mostly also in quantitative ways); sociologists view it as a social and cultural construct, whereas psychology looks at it as a cognitive and behavioral phenomenon. Each discipline 
commonly utilizes their own terms about risks, while keeping different perspectives on what it is [4]. Also, risk communication is hampered by this semantic ambiguity not only in the communication between stakeholders and lay people, but also between different scientific disciplines working together to manage risk $[4,5]$.

Knowledge management plays an important role in risk issues, for example risk analysis and risk regulations, and knowledge transfer and knowledge sharing are important parts in risk communication. Explicit knowledge is easier to communicate which clarifies the particular problem with newly emerging risks, where explicit or generalized knowledge is unfortunately not available [6].

\section{Knowledge about hazard and risk}

In the historical perspective, no notion of risk is to be found in traditional cultures: preindustrial hazards or dangers like famines, plagues, or natural disasters were experienced as pregiven. They came from "others" - gods, nature, or demons [7]. However, when carefully reinterpreting the historical perspective, it appears that the notion of risk was already there, albeit implicitly, because one does not have to know the origin of a hazard in order to apply mitigation measures to avoid harm and suffering. One could even argue that sacrificing a virgin to please the god to avoid plagues or nature catastrophes involved an understanding and/or management of a hazard. It may well be that preventive actions taken today will in the future be regarded as similarly useless and surprisingly little evidence-based as sacrificing virgins to prevent plagues is regarded today.

In the historical perspective, first with the beginning of societal attempts to control risk, and particularly with the idea of steering toward a future of predictable security, the consequences of risk became political issues. Thus, it is a societal intervention - in the form of decision-making attempts to transform incalculable hazards into calculable risks.

Nowadays, it is necessary to separate the notions of risk and hazard. Knowledge about the hazard should be present before labeling any event as "risky." Hazard can be defined as an event [8] but it can also be considered as a condition or factor with a potential for causing an event, thus, as a synonym to danger. In this way, hazard is a qualitative term that tells whether exposure to a chemical or drug or certain behavior such as physical inactivity has the potential to cause an undesirable outcome on human health or other things we value, e.g., the environment. The evaluation of an event as a hazard is a mix of objective and subjective data, with the latter depending on individual or at least cultural preferences. The scientific component of the evaluation of the hazard aims to be objective and with a dichotomous (qualitative) outcome, namely being hazardous or not. Scientific uncertainty adds to complexity, if for instance studies on the carcinogenicity of a chemical are controversial, which may add some subjective elements (different researchers interpreting the same studies in different ways) and a categorical scale replacing the dichotomous one to express the level of scientific uncertainty. Nevertheless, researchers then continue to collect further evidence until ultimately the hazard can be established or rejected. Objectively, hazards can be fatal or life-threatening, leading to disability or only to temporary discomfort; hence, classified according to dimensions of 
impact on life and of reversibility. The assessment of severity is a quantitative part of hazard evaluation, and the subjective acceptance is the qualitative part. It is subjective because it is the individual's own judgment reflecting their values and preferences.

On the basis of these facts, a dichotomous hazard will be transformed into a quantitative risk term [9]. In all disciplines, there are two most known concepts of risk definition: the probability of occurrence and severity of the undesirable outcome. Under this approach, risk is the probability function that reflects in quantitative terms the likelihood that a hazard manifests itself while as we have alluded to earlier, the undesirable outcome is the hazard.

\section{Dealing with knowledge during risk assessment}

Normally, scientific risk assessment should be performed before labeling any event as "risky." Identification of a hazard is the first step in the risk assessment process. Before identifying the hazard, potential disease or outcome clusters need to be found. For example, before 1989 only one disease outbreak per year was identified in a population of over 60 million people in the Philippines. A surveillance system was set up in 1989 and in 1995 more than 80 disease outbreaks were identified [10]. This means that risks cannot be described as such unless there are procedures to identify or measure outcome clusters or hazards (perceived or real) and our vulnerability to them. Another point worth mentioning is that if you do not know the hazard, you cannot perceive the related risk. The second stage of the risk assessment process entails an estimate of the associated level and extent of potential harm which together with the expected probability of an unwanted event are important, because the evaluation of the acceptability of the options for mitigating the identified risk will usually depend on how much harm the hazard we identify can be estimated to make. For the assessment procedure, two forms of assessment are discussed in detail: the technical procedure and the observational approach.

In the technical procedure like engineering, material properties, technical performances, or technical measurements are based on tests or experiments. The results are countable from numerous versions of repeated experiments. The experimental approach allows estimating a small confidence interval considering probabilistic calculations. One example is the overall construction procedure in the design of the roof for a building. First, the total design load on the roof must be computed. The different loads could typically be: self-weight, wind load, and snow load. A design load can then be computed as the sum of these loads. However, as the loads are stochastic in nature, each load is multiplied by a coefficient that accounts for the lower probability that all loads are maximal at the same time. Strengthening the construction is intended to reduce the risk of failure, but will never eliminate it, and the design of a construction is, therefore, a balance between strength and acceptable risk for failure.

In the observational approaches of epidemiological and public health studies, the outcomes of interest are often death or diseases like cancer, myocardial infarction, or infectious diseases. There may be several causes for having that outcome and several hazards may need to be considered for the risk assessment. One cause hardly ever leads to only one single outcome. Stress at work, for example, is a risk factor for myocardial infarction. But other risk factors like hypertension, overweight, unhealthy blood lipid profile, or lack of physical activity are 
also risk factors for myocardial infarction and all of them may be related to stress at work. On the other hand, overweight has more than one adverse consequence, including a higher risk of some cancers or diabetes. The complexity is topped by the inherent and much higher heterogeneity in susceptibility to an adverse outcome in a population of humans than among construction parts in engineering. Risk assessment is still possible; and for the quantitative estimation of absolute or relative risk, epidemiological measures are used by calculating disease rate and comparing rates of exposed and unexposed groups [11].

Risk assessment in occupational health is traditionally based on a four-stage process: hazard identification, exposure assessment, dose-response assessment, and risk characterization. However, risk assessment is typically put into the broader context of managing occupational risks and often includes ongoing monitoring and evaluation of the effectiveness of any initiative to decrease risk to an acceptable level. An acceptable risk level is defined not solely by health arguments but, especially in the case of carcinogenic agents that have stochastic health effects, such as hexavalent chromium exposure in electroplating causing lung cancer, also includes considerations on financial and technical feasibility. Since the main reason of risk assessment is to determine what, if any, measures should be taken by the employer to prevent adverse health effects in workers, it is common to integrate risk assessment and risk management in occupational health practice $[12,13]$. Occupational health and safety is, therefore, one of the most regulated areas in terms of legal requirements for risk assessment [14].

Medical and environmental risk assessments to guide risk management become increasingly challenging, when certain exposures have both risks and benefits, or when the hazard is intended or inherent in a specific scenario. Medical application is a common example of balancing benefit and harm. The use of computed tomography (CT) with its high resolution can clearly lead to better diagnosis and planning of treatment and then becomes lifesaving, but given its exposure to ionizing radiation, a well-known carcinogen, endorses recommendations that unnecessary examinations need to be avoided and optimal dose adjustment, for example for children, is to be applied [15]. However, there may clearly be a huge risk related to avoiding the hazard of undergoing a CT examination, for instance, due to a delayed detection of cancer. Also, in environmental health not all hazards are entirely avoidable, but risk assessment can guide policy decisions insofar as where to set priorities for an acceptable level of risk and of how much risks can be reduced.

\section{Dealing with knowledge in risk perception}

Identifying hazard and severity of a damage has direct consequences for risk perception: "Perception is a process by which individuals select, organize and interpret stimuli to generate a coherent and meaningful picture" [16]. In contrast to risk assessment, which can have a scientific basis with a structure and procedures, risk perception is subjective, involves affects and there are many factors that can influence the way a risk is perceived.

Literally, risk cannot be perceived. Therefore, psychological research focusing on risk perception explores how judgments about the riskiness of an event, substance, agent, or technology are made in which cognitive, affective, and moral processes are involved. Although the first risk perception studies were conducted more than 50 years ago, the concept of "perceived risk" 
only began to gain popularity in the mid-1970s [17]. Slovic's approach known as the psychometric paradigm aims at the "quantitative description of the cognitive and evaluative mental structure of risk and its determinants" [18]. His research focuses on "what people mean when they say that something is (or is not) 'risky', and to determine what factors underlie those perceptions" [19]. It focuses on the beliefs laypersons hold with regard to how chemicals cause health risks. For instance, laypersons are less sensitive to dose-response relationships compared to toxicologists suggesting that laypersons do not differentiate between the qualitative hazard and the quantitative risk, and therefore do not see risk as something that can be increased or reduced due to interventions or changes in exposure levels. This misconception is a continuing challenge in medical risk communication because most interventions, especially health promoting interventions, reduce but do not eliminate risks. Risk of an adverse event can generally only be reduced, but specific risks related to a certain hazard might be eliminated if the hazard is eliminated, though it may take some time. If you quit smoking, after 20 smokeless years, you will have vascular disease mortality comparable with never smokers [20], but like the rest of the population you still may die of vascular disease because of other hazards leading to the same adverse event.

From the rational point of view, to evaluate a risk, you need to know something about the hazard, assess probabilities as well as consequences of the negative outcome. In fact, however, intuitive risk judgment has a strong affective component, and it is associated with moral concerns and may neglect any probability consideration in risk appraisal. Doing something about your personal risk depends on how you understand the risk. This is a subjective exercise including the compilation of the more objective information on hazard and risk in combination with individual assessments on severity of risk and potential side effects, and last but not least on personal values and preferences.

From the sociological point of view, probabilistic risk assessment alone is unsociological. Sociological understanding of risk needs additional social, cultural, and historical contexts. Sociology explains how risks are handled in a society and might thereby clarify potential public misperceptions of risk. When technically defined risks are not contextually generated, public risks understanding will be defined as wrong, if it differs from the factual experts' opinion. From the sociological point of view, it is an error not considering contextual factors like traditions, culture, norms, etc. even though that does not mean that the factual knowledge is wrong. The role of sociology, when it comes to risk, is to explain why errors in dealing with risk in a society occur but not the truth behind them. Implication of this perspective deals with risk communication. The factual knowledge about specific risks needs to be understood and communicated. Sociology emphasizes that when dealing with communication it is important to consider different segments of the public understanding of risks to avoid misperception. Sociological amplification of risk explains how risks and events or accidents interact with psychological, social, institutional, and cultural processes, and often increase or decrease risk perception, public concern, and thereby risk behavior. The objective risk assessment provides information about the risk, but for a sociologist the task is to analyze how this information is understood and reflected in practical social actions in the public. Risks and hazards are sociocultural events and they are not only neutral facts that generate specific signals. It should be considered that also an assessment of a risk can be seen as a construction of a risk and hazard. This implies for sociology to see and explain risk as an overall product of social and cultural processes [21]. 


\section{Knowledge management considering different disciplines}

All risk concepts of the different disciplines have one element in common; the distinction between reality and uncertainty. Figure 1 illustrates the tasks of the different disciplines in the process of risk management. Engineering and occupational health focuses on hazard and risk identification (explicit knowledge). Sociology looks at the risk on humans and society (social knowledge). Psychology works with risk perception and manages risk on a personal level (individual knowledge). The latter two disciplines rely on the first to identify and describe risk as objective as possible, and the former depend on the psychology and sociology to translate their observations and calculations into something usable for individuals and society. Therefore, it is essential that these disciplines keep their definition and taxonomy of risk knowledge. However, interaction and knowledge sharing is important for the overall risk management process.

The engineer tells the occupational hygienist technical details for the risk assessment; the occupational hygienist communicate risk assessment results to medicine to allow the best treatment for the exposed individual; the doctor needs to explain the information to the patient. Finally, the patient should perceive the risk in that manner to do the right action. Already for a straightforward treatment, a long chain of knowledge transfer needs to work. However, risk

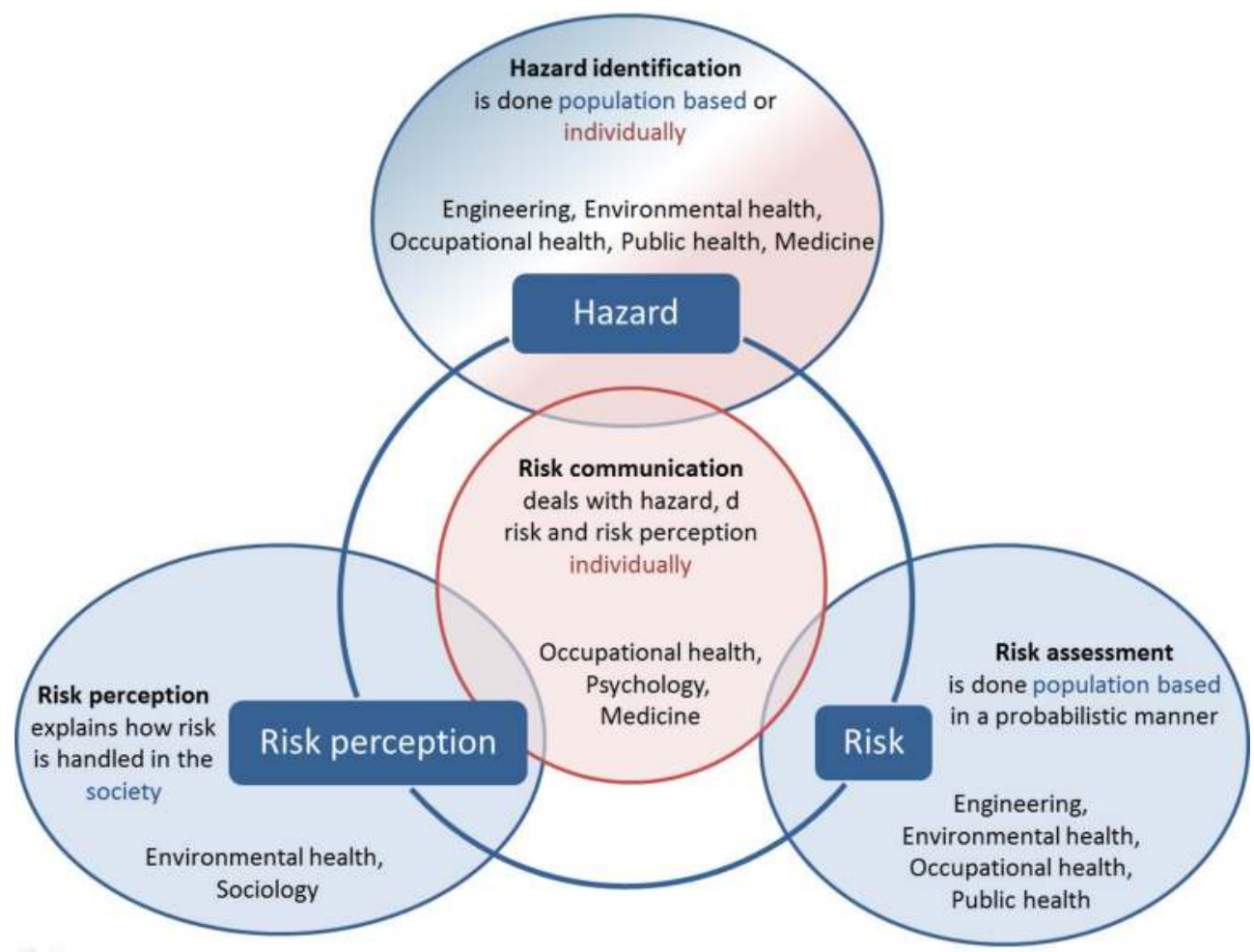

Figure 1. Concepts of considered disciplines while defining risk. 
assessment and management to reduce the risks is rarely straightforward, especially when scientific uncertainty and, at the same time, competing benefits and risks come into play. A recent example is management of potential risks related to the use of electronic cigarettes [22, 23], for which on the one hand, long-term adverse health effects are expected, but on the other hand, electronic cigarettes are also expected to be safer than conventional cigarettes to facilitate to quit smoking. Public health researchers mainly request strict regulation to minimize potential future health effects and avoiding electronic cigarettes to become a new socially acceptable way of smoking, especially among youngsters, and thereby torpedoing the efforts for achieving a smoke-free environment.

Therefore, it is very important to understand underlying terminology from different disciplines. But even more important is to understand their tasks and their views on the topic. For example, the role of sociology "to explain why errors occur but not the truth behind them" clarifies that communication is more important for the sociological perspective than the risk assessment procedure itself, even though both parts are necessary for the overall risk management. If these different views are not taken into account, conflicts and misunderstandings can happen.

In knowledge management, knowledge creation tools were often criticized. One critique is that most tools hide or eliminate important contextual information [24]. Furthermore, it could be shown that individual communication skills have more importance for perceived quality of risk knowledge sharing than the used technical systems [6]. Additionally, lack of time or awareness for the importance of sharing knowledge, missing communication skills, as well as differences in education and culture are seen as the most important barriers for interdisciplinary work [25]. In our opinion, collaborating researchers need to understand their used terms but also have to understand why there are differences. It is very important to know the terminology, tasks, and perspectives from different disciplines. Different terminology can be dealt with in a wiki development, a website that provides collaborative work on terminologies. However, further research is necessary on how to deal with different discipline-related aims or perspectives in the process of risk management.

Most differences between the disciplines are dealing with risk assessment. All disciplines have the theoretical wish to estimate the real quantitative risk and all disciplines agree that this is difficult to achieve or sometimes not even possible. Disciplines typically using probabilistic approaches, such as engineering or occupational health, define risks mathematically and more objectively. Consequently, these disciplines emphasize the importance of external validity and standardized procedures. Observational research is often connected with a black box phenomenon and is sometimes evaluated as giving less support to evidence than experiments. The presentation of results is more complex and difficult to understand and to trust. Consequently, in these disciplines, problems in objectivity and communication are more obvious. The cognitive approach seen in psychology and social sciences focuses more on the perception of risk. They evaluate the understanding of different risk presentations and look into emotions and cognitive processes while collecting risk assessment information. Due to the fact that risk assessment is seen as less objective, risks are seen as expectations or predictions. However, all disciplines agree that risk assessment should be as objective as possible. To allow for this, evidence-based information must be used to identify hazards and to assess 
dose-response relationships, while exposure assessment should be based on documented, preferably quantitative, measurable, and representative data.

\section{Conclusion}

There is a broad common denominator between the disciplines; hazard is a negative event or condition; for most risk definitions, probability and severity of the risks are important; and finally risk perception is seen as subjective and a mental construct. Risk assessment should be evidence-based, preferably quantitative, measurable, and based on representative data. Assessment of concerns and perceptions is important as well but should be done separately.

Differences can be seen with regard to risk assessment between disciplines with cognitive and probabilistic approaches. However, differences are connected to the interpretation and terminology but not to procedures. Coping with scientific controversies is an important factor in risk management. Different scientific institutions often come to different conclusions and it is easy to select a specific opinion that supports only one view of risk. A transparent risk assessment framework considering different scientific perspectives is important to deal with controversies in risk science.

Knowledge management in risk management needs to account for different use of terminologies by different disciplines. It is important to consider the diversity of tasks and perspectives of various fields when defining terminologies and distributing work. A transparent risk assessment process can only be ensured with an acceptance and appreciation of terminologies and perspectives from different disciplines.

\section{Author details}

Gabriele Berg-Beckhoff ${ }^{1 *}$, Peter Wiedemann²,3 Balázs Ádám4, Joachim Schüz ${ }^{5}$, Kristian Breum Ølgaard ${ }^{6}$, Pernille Tanggaard Andersen ${ }^{1}$, Steven Ndugwa Kabwama ${ }^{1}$ and Jesper Bo Nielsen

*Address all correspondence to: gbergbeckhoff@health.sdu.dk

1 Unit for Health Promotion Research, University of Southern Denmark, Odense, Denmark

2 Science Forum EMF, Berlin, Germany

3 University of Wollongong, Wollongong, Australia

4 Department of Preventive Medicine, Faculty of Public Health, University of Debrecen, Hungary

5 Section of Environment and Radiation, International Agency for Research on Cancer (IARC), France

6 Ramboll Energy -Offshore Wind, Denmark

7 Research Unit for General Practice, University of Southern Denmark, Odense, Denmark 


\section{References}

[1] Grey. What is Knowledge Management? The Knowledge Management Forum [Internet]. 1996. Available from: http://www.km-forum.org/t000008.htm [Accessed: July 14, 2016]

[2] Zipperer L, Amori G. Knowledge management: An innovative risk management strategy. Journal of Healthcare Risk Management. 2011;30(4):8-14. DOI: 10.1002/jhrm.20064

[3] Slovic P. Trust, emotion, sex, politics, and science: surveying the risk-assessment battlefield. Risk Analysis. 1999;19:689-701

[4] Althaus CE. A disciplinary perspective on the epistemological status of risk. Risk Analysis. 2005;25:567-588. DOI:10.1111/j.1539-6924.2005.00625.x

[5] German Institute for Risk Evaluation - Bundesinstitut für Risikobewertung (BfR). Ulbig E, Hertel RF, Böl GF (Eds) Kommunikation von Risiko und Gefährdungspotenzial aus Sicht verschiedener Stakeholder. Berlin; BfR Hausdruckerei Dahlem; 2010

[6] Rodriguez E, Edwards J. People, technology, processes and risk knowledge sharing. Electronic Journal of Knowledge Management. 2010;8(1):139-150

[7] Beck U. Risikogesellschaft. Auf dem Weg in eine andere Moderne. Frankfurt a.M: Suhrkamp Verlag; 1986

[8] Stewart M, Melchers RM. Probabilistic Risk Assessment of Engineering Systems. London, Champan \& Hall. 1997

[9] Luhmann N. Risk - A Sociological Theory. Meuchen, DEU: Walter de Gruyter; 2011

[10] White ME, Mac Donnel SM. Public health surveillance in low and middle-income countries. In: Teutsch SM, Churchill RE, editors. Principles and Practices of Public Health Surveillance. New York: Oxford University Press; 2000. pp. 287-315

[11] Gordis L. Epidemiology. Philadelphia: Elsevier Saunders; 2014

[12] Aw TC, Gardiner K, Harrington JM. Occupational Health. 5th ed. Oxford: Blackwell Publishing; 2007

[13] International Labour Organization (ILO). Occupational Safety and Health Convention, 1981 (No. 155). Geneva: ILO; 1981

[14] International Labour Organization (ILO). OHS Management System: A Tool for Continual Improvement. Geneva: ILO; 2011

[15] Thierry-Chef I, Dabin J, Friberg EG, Hermen J, Istad TS, Jahnen A, Krille L, Lee C, Maccia C, Nordenskjöld A, Olerud HM, Rani K, Rehel JL, Simon SL, Struelens L, Kesminiene A. Assessing organ doses from paediatric CT scans - a novel approach for an epidemiology study (the EPI-CT study). International Journal of Environmental Research and Public Health. 2013;10:717-728. DOI: 10.3390/ijerph10020717 
[16] Zimbardo PG, Gerrig R. Psychology and Life. United States: Allyn \& Bacon, Incorporated; 2011

[17] Slovic P, Fischhoff B, Lichtenstein S. Cognitive processes and societal risk taking. In: Jungermann H, Zeeuw Gd, editors. Decision Making and Change in Human Affairs. Dordrecht: Riedel; 1977. pp. 7-36

[18] Jungermann H, Slovic P. Charakteristika individueller Risikowahrnehmung. In: Krohn G, Krücken G, editors. Riskante Technologien. Reflexion und Regulation. Einführung in die sozialwissenschaftliche Risikoforschung. Frankfurt am Main; Surhkamp: 1993

[19] Slovic P. Perception of risk. Science. 1987;236:280-285

[20] Kenfield SA, Stampfer MJ, Rosner BA, Colditz GA. Smoking and smoking cessation in relation to mortality. JAMA. 2008;299:2037-2047. DOI: 10.1001/jama.299.17.2037

[21] Lidskog R, Sunderqvist G. Sociology of risk. In: Roeser S, Hillerbrand R, Sandin P, Peterson M, editors. Handbook of Risk Theory - Epistemology, Decision Theory, Ethics, and Social Implication of Risks. Dordrecht, Netherlands: Springer; 2012. pp. 1001-1028

[22] WHO World Health Organization. Electronic Nicotine Delivery Systems [Internet]. 2004. Available from: http://apps.who.int/gb/fctc/PDF/cop6/FCTC_COP6_10-en.pdf [Accessed: July 7, 2014]

[23] Hawkes N. WHO review exaggerated dangers of e-cigarettes, say specialists. British Medical Journal. 2014;349:g5501. DOI: 10.1136/bmj.g5501

[24] Cooper LP. A research agenda to reduce risk in new product development through knowledge management: A practitioner perspective. Journal of Engineering and Technology Management. 2003;20:117-140

[25] Ruzic-Dimitrijevic L. Risk assessment of knowledge management system. Online Journal of Applied Knowledge Management. 2014;3(2):114-126 
